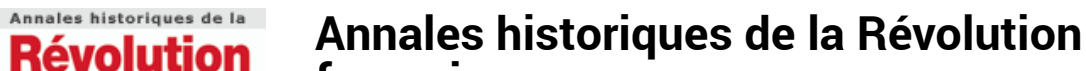

française française

332 | avril-juin 2003

Une révolution du pouvoir exécutif ?

\section{Roger BERGERET et Jean MAUREL, L'avocat Christin, collaborateur de Voltaire (1741-1799), préface de Claude-Isabelle BRELOT}

Lons-le-Saunier/Saint-Claude, Société d'émulation du Jura/Amis du vieux Saint-Claude, 2002, 153 p.

Jean Bart

\section{OpenEdition}

\section{Journals}

Édition électronique

URL : https://journals.openedition.org/ahrf/5603

DOI : $10.4000 /$ ahrf.5603

ISSN : 1952-403X

Éditeur :

Armand Colin, Société des études robespierristes

Édition imprimée

Date de publication : 1 juin 2003

Pagination : 195-196

ISSN : 0003-4436

Référence électronique

Jean Bart, « Roger BERGERET et Jean MAUREL, L'avocat Christin, collaborateur de Voltaire (1741-1799), préface de Claude-Isabelle BRELOT », Annales historiques de la Révolution française [En ligne], 332 | avriljuin 2003, mis en ligne le 22 avril 2008, consulté le 23 avril 2022. URL : http://journals.openedition.org/ ahrf/5603 ; DOI : https://doi.org/10.4000/ahrf.5603

Ce document a été généré automatiquement le 23 avril 2022

Tous droits réservés 


\section{Roger BERGERET et Jean MAUREL, L'avocat Christin, collaborateur de Voltaire (1741-1799), préface de Claude-Isabelle BRELOT}

Lons-le-Saunier/Saint-Claude, Société d'émulation du Jura/Amis du vieux Saint-Claude, 2002, $153 \mathrm{p}$.

\section{Jean Bart}

1 On connaissait l'action menée par Voltaire au cours des dernières années de sa vie en faveur des «serfs du Haut-Jura». Mais la célébrité du patriarche de Fernay laissait quelque peu dans l'ombre l'initiateur et le principal artisan de la campagne engagée sans succès immédiat - pour les libérer du poids de la mainmorte, cet avatar du vieux servage : Charles Gabriel Frédéric Christin, vilipendé par Dom Benoît, l'historien - ô combien partial - de l'abbaye de Saint-Claude à la fin du XIX ${ }^{e}$ siècle, au plus fort moment des querelles religieuses. Sa personnalité et son destin sont heureusement mis en lumière par l'oeuvre commune de deux professeurs sanclaudiens, publiée grâce à la collaboration de deux sociétés savantes locales.

2 Cet élégant petit livre ne nous fait rien ignorer de la vie de cet avocat, commencée au sein de la bonne bourgeoisie de la basoche, à Saint-Claude, et interrompue prématurément par l'incendie de la ville, à la fin du Directoire. Mais il ne s'agit pas seulement d'une sorte d'hommage inspiré par un patriotisme local de bon aloi. Les auteurs ont cherché et réussi à donner une dimension beaucoup plus vaste et séduisante à leur étude biographique, en situant Christin, d'une part au sein de la seconde génération des Lumières dont il a été le relais en Franche-Comté, et, de l'autre, dans le mouvement révolutionnaire. Ceci, grâce au dépouillement d'archives jusqu'alors inexplorées ou peu sollicitées, en particulier des nombreuses lettres adressées par Voltaire à « son cher petit philosophe », alias « avocat de l'humanité ».

Les deux hommes se sont rencontrés au début des années soixante, après l'envoi fait par le jeune juriste tout frais émoulu de l'université, d'un mémoire, aujourd'hui 
disparu, sur la mainmorte frappant les manants des terres de l'ancienne abbaye. Ainsi commença une collaboration qui ne s'achèvera qu'à la mort de Voltaire, Christin étant d'ailleurs choisi comme son exécuteur testamentaire. Devenu juge seigneurial de Ferney et prenant une part importante, d'après les auteurs, à la rédaction du Commentaire du célèbre Livre des délits et des peines de Beccaria, l'avocat sanclaudien "plus riche de talent que d'argent" - entraîne son vieil ami dans le combat pour la liberté des main-mortables; combat perdu au bout d'une dizaine d'années, mais qui fut "le premier engagement prérévolutionnaire de Christin». De fait, à partir de ce moment-là celui-ci participe, à travers bien des péripéties, à la lutte engagée au sein de la bourgeoisie urbaine pour le pouvoir municipal, avant d'être élu député du Tiers du bailliage d'Aval aux États généraux.

4 Commence alors une autre phase, non étudiée jusqu'alors, de la vie de Christin. S'il fut un Constituant assidu, ses prises de position à l'Assemblée ne semblent pas des plus remarquables. Mais il demeure fidèle à ses idées et se déclare favorable à la suppression des droits féodaux sans indemnité. C'est aussi par fidélité à la mémoire de son célèbre ami, qu'il intervient, en 1791, pour s'opposer au partage des restes de Voltaire revendiqués par plusieurs communes, et qu'il appuie la décision de le «panthéoniser ». Très tôt, il apparaît comme un modéré, «à la recherche du centre ». Membre du Club des Feuillants, il semble craindre particulièrement la violence des foules. À l'automne 1791, alors que s'installe la Législative, Christin, élu juge du district, revient dans sa ville natale qu'il ne quittera plus, pour exercer des fonctions qui lui convenaient parfaitement. Ensuite, il se tient prudemment à l'écart du mouvement révolutionnaire, et, en 1793, entre en conflit avec les jacobins locaux, en particulier avec Lémare, un ancien prêtre issu d'une famille mainmortable, chargé de « régénérer » le département du Jura. Emprisonné, accusé d'être « du côté droit », tel un « aristocrate bourgeois », il échappe à la guillotine et se retrouve, après Thermidor, nommé au sein de la municipalité de sa ville, où il se déchaîne contre ses anciens adversaires, ce qui lui vaut d'être élu commissaire du Directoire en décembre 1795. Cependant, à la faveur du coup d'État du 30 prairial an VII, son ennemi personnel, Lémare, revient au sein de l'administration départementale... jusqu'au coup d'État de Brumaire. Mais entre-temps, Christin meurt asphyxié dans la cave de sa maison où il s'était réfugié lors du terrible incendie qui détruisit Saint-Claude le 19 juin 1799.

5 Les auteurs insistent sur le fait que leur héros est mort sinon pauvre, du moins peu fortuné. De fait, n'ayant pas acquis, semble-t-il, de biens nationaux ni spéculé d'aucune façon, il n'a guère profité, à la différence de bien d'autres, des possibilités offertes à la bourgeoisie pour s'enrichir. Son seul luxe était sa bibliothèque, disparue dans les flammes. En définitive, Christin serait, par conviction, resté fidèle aux idéaux de sa jeunesse, à une sorte de "libéralisme voltairien", aussi éloigné de la morgue des parvenus que des débordements de ceux qui, aux yeux de son maître, constituaient la « canaille». 